\title{
Azilsartan is More Effective as Compared to Olmesartan in Hemodialysis Patients with Uncontrolled Hypertension
}

\author{
Akira Ukimura ${ }^{1,2 *}$, Hirohisa Matsuda², Yoko Yamauchi ${ }^{2}$, Kazuhisa Yamamoto ${ }^{2}$, Kei Hirai ${ }^{2}$, Nobuyuki Ueno ${ }^{2}$, Hideaki Yasuda and Shuta Ono ${ }^{2}$ \\ ${ }^{1}$ General Internal Medicine, Osaka Medical College, Japan \\ ${ }^{2}$ Sanko Hospital Group, Japan
}

\begin{abstract}
Background: Azilsartan is a new angiotensin receptor blocker with more continuous antihypertensive effects. The objective of this study was to demonstrate the efficacy and safety of azilsartan in hemodialysis patients with uncontrolled hypertension.

Methods: Twenty-two hemodialysis patients treated with multiple antihypertensive drugs including olmesartan (20$40 \mathrm{mg} /$ day) were enrolled in this retrospective observational study. Blood pressure was measured in the morning and evening for a week at baseline and after switching from olmesartan to azilsartan. The patients' mean blood pressure at baseline was $171 / 71 \mathrm{mmHg}$. Olmesartan (20-40 mg/day) was switched to azilsartan with the same dose. An electrocardiogram, an echocardiogram, and measurement of the ankle-brachial index were performed in all patients, and the echocardiogram showed left ventricular hypertrophy in all patients. Home-measured blood pressure, heart rate, and serum potassium were followed for 9 months after switching.
\end{abstract}

Results: Systolic blood pressure was significantly decreased at 1, 3, 6, and 9 months after switching. Diastolic blood pressure was significantly decreased at 3 and 6 months after switching. Switching did not alter the serum potassium level.

Conclusions: Switching from olmesartan to azilsartan significantly and safely decreased home-measured blood pressure in hemodialysis patients.

Keywords: Hemodialysis; Uncontrolled hypertension; Olmesartan; Azilsartan

\section{Introduction}

Hypertension is a major risk factor for cardiovascular events in the general population. Hypertension is also very common in hemodialysis patients and is a risk factor for the development and progression of left ventricular hypertrophy, cardiovascular disease, and total mortality [13]. Using various definitions of hypertension, $60-90 \%$ of hemodialysis patients are estimated to have hypertension [4,5]. The majority of hemodialysis patients are given antihypertensive drugs, although not all patients achieve the target blood pressure (BP) [6-8]. We control the BPs of about 400 hemodialysis patients in three outpatient hemodialysis units of Sanko Hospital Group in Osaka, Japan, usually using multiple antihypertensive drugs in the majority of patients in the units, but BP is poorly controlled in about $10 \%$ of patients with multiple antihypertensive drugs.

On the other hand, home BP measurement is recommended by guidelines for hypertension management [9-11]. BP varies greatly during the interdialysis period, and BP is frequently overestimated in outpatient hemodialysis units. It has been reported that home BP measurement may be useful for adjusting blood pressure control among hemodialysis patients [12].

Azilsartan is a new angiotensin receptor blocker (ARB) that selectively inhibits the binding of angiotensin II (AII) to AII type 1 receptors $[13,14]$. It has been reported that azilsartan provides greater $\mathrm{BP}$ reduction than candesartan over the entire 24-h monitoring period, as well as during the specific daytime, night-time, and early morning periods, by analysis of ambulatory blood pressure monitoring records $[15,16]$. The objective of this study was to demonstrate the efficacy and safety of switching from olmesartan to azilsartan in hemodialysis patients with uncontrolled hypertension.

\section{Materials and Methods}

This study was a retrospective observational study. Hemodialysis patients with uncontrolled hypertension who had been treated with multiple antihypertensive drugs including olmesartan (20-40 mg/day) for more than 3 months were enrolled. BP was measured twice a day, in the morning and evening, at home for a week by the patients, so BP was measured 14 times a week. Recordings were carried out in a sitting position using an automatic device that was based on the cuffoscillometric method after taking a least a 5 -min rest. The patients were asked to record the BP measured at home with their own machine. The average home-measured blood pressures for a week before and after switching were then evaluated. Patients whose average systolic $\mathrm{BP}$ was $>160 \mathrm{mmHg}$, or temporary systolic $\mathrm{BP}$ was $>180 \mathrm{mmHg}$ were enrolled. An electrocardiogram (ECG), ankle-brachial index (ABI), and echocardiogram were recorded at baseline and at the 6 month follow-up. Home-measured blood pressure, heart rate, serum sodium, and serum potassium levels were followed for 9 months. The protocol was approved by the independent ethics committee of Sanko Hospital Group. Patients were given a detailed explanation of the study protocol and aims before being enrolled, and their written, informed consent was obtained.

*Corresponding author: Akira Ukimura, Department of General Internal Medicine Osaka Medical College, 2-7 Daigaku-machi, Takatsuki 569-8686, Japan, Tel: +8172-683-1221; Fax: +81-72-684-7386; E-mail: in3011@poh.osaka-med.ac.jp

Received December 28, 2014; Accepted January 28, 2015; Published February 03, 2015

Citation: Ukimura A, Matsuda H, Yamauchi Y, Yamamoto K, Hirai K, et al (2015) Azilsartan is More Effective as Compared to Olmesartan in Hemodialysis Patients with Uncontrolled Hypertension. J Nephrol Ther 5: 193. doi:10.4172/2161-0959.1000193

Copyright: (c) 2015 Ukimura A, et al. This is an open-access article distributed under the terms of the Creative Commons Attribution License, which permits unrestricted use, distribution, and reproduction in any medium, provided the original author and source are credited. 
$\mathrm{BP}$, serum sodium, and serum potassium levels are expressed as means \pm standard error. A mixed model pairwise comparisons test with the Bonferroni correction compared to before switching was performed. A P value $<0.05$ was considered significant. Age, duration of hemodialysis therapy, and echocardiogram data are expressed as means \pm standard deviation. All statistical analyses were performed using IBM SPSS Statistics 21.0 (Armonk, New York, USA).

\section{Results}

The baseline characteristics of the 22 patients are shown in Table 1. The average age was $67.0 \pm 10.0$ years, and the mean duration of hemodialysis therapy was $59.5 \pm 31.6$ months. The etiology of end-stage renal disease was: $10(45 \%)$ diabetes mellitus, 7 (32\%) glomerulonephritis, 4 (18\%) renal sclerosis, and 1 (5\%) polycystic kidney. Patients with atrial fibrillation were excluded. Echocardiography showed left ventricular hypertrophy in all patients, but ECG findings showed left ventricular hypertrophy in 7 (32\%) patients. The ABI was abnormal in $4(18 \%)$ patients. All patients received a combination of antihypertensive drugs including olmesartan $(30.7 \pm 5.4 \mathrm{mg}) ; 3$ patients received 6 antihypertensive drugs, 5 received 5 antihypertensive drugs, 9 received 4 antihypertensive drugs, 4 received 3 antihypertensive drugs, and 1 received 2 antihypertensive drugs. Twenty patients were treated with calcium channel blockers. Calcium channel blockers were contraindicated in 2 patients because of side effects.

The mean systolic blood pressure before switching was $170.7 \pm$ $12.5 \mathrm{mmHg}$. The mean diastolic blood pressure before switching was $71.5 \pm 7.5 \mathrm{mmHg}$. Systolic blood pressure was significantly decreased at 1 month $(160.0 \pm 14.2 \mathrm{mmHg} ; \mathrm{p}<0.001), 3$ months $(158.2 \pm 14.0$ mmHg; $\mathrm{p}<0.001), 6$ months $(157.4 \pm 14.8 \mathrm{mmHg} ; \mathrm{p}<0.001)$, and 9 months $(153.0 \pm 17.3 \mathrm{mmHg}$; $<<0.001)$ after switching. Diastolic blood pressure was significantly decreased at 3 months $(69.2 \pm 7.3 \mathrm{mmHg}$; $\mathrm{p}<0.05)$ and 6 months $(67.7 \pm 7.4 \mathrm{mmHg} ; \mathrm{p}<0.01)$ after switching. Diastolic blood pressure was $69.2 \pm 7.3 \mathrm{mmHg}$ (not significant) at 1 month and $67.3 \pm 6.7 \mathrm{mmHg}$ at 9 months (not significant) after switching. Switching from olmesartan to azilsartan did not alter serum sodium or serum potassium levels. These data are shown in Figure 1. ECG, ABI, and echocardiography 6 months after switching showed no significant differences compared to baseline (data not shown). We changed dry weight in only one patient during the study. We did not change any other conditions of hemodialysis during the study. There were no cardiovascular events during 9-month follow-up.

\section{Discussion}

Many trials have shown the cardiovascular benefits of lowering blood pressure in the general population. Ciccone et al. reported that age and sex could influence the noninvasive parameters to assess the cardiovascular risk profile [17]. It has been reported that the mortality rate for hemodialysis patients is $20 \%$ during the first year and $70 \%$ after 5 years of treatment [1-5]. Cardiovascular disease is common and the leading cause of morbidity and mortality in hemodialysis patients, since hemodialysis patients have multiple risk factors [7]. Patients with atrial fibrillation were excluded in the study, because atrial fibrillation is clinically significant arrhythmia and the relationship between atrial fibrillation and physical activity was reported [18]. It has been reported that treatment with antihypertensive drugs should be considered for hemodialysis patients to reduce the very high cardiovascular morbidity and mortality rate in this population $[6,7,19]$. BP measurement is particularly important in hemodialysis patients, because disparate outcomes are obtained depending on the timing, location, frequency, and technique of BP measurement [8,9]. Difficulties in making an accurate diagnosis of hypertension in hemodialysis patients arise in part due to large swings in BP with the hemodialysis procedure [20]. High pre-hemodialysis systolic BP is also a risk factor for death, but the target levels are not known [21,22].

Ambulatory blood pressure monitoring provides not only static and but also dynamic information about BP that should be considered to ensure effective management of hypertension and cardiovascular diseases, but ambulatory blood pressure monitoring is uncommon $[15,23]$. Moriya et al. reported that one-point measurement of BP is insufficient to evaluate hypertension and the prognosis of hemodialysis patients, and weekly averaged blood pressure is a useful marker because it averages fluctuations of BP over one week [24]. It has also been reported that weekly averaged $\mathrm{BP}$ could be a good prognostic marker of the incidence of both cardiovascular events and all-cause mortality in hemodialysis patients [25]. It has been reported that home-measured $\mathrm{BP}$, especially systolic BP in the morning on hemodialysis days, can provide pivotal information for the management of hemodialysis patients [26,27]. Thus, home-measured BP was evaluated for a week before and after switching.

In hemodialysis patients, non-volume mechanisms, such as activation of the renin angiotensin system, are important for sustaining

\begin{tabular}{|c|c|}
\hline \multicolumn{2}{|c|}{ Baseline Characteristics of 22 patients } \\
\hline Age(years) & $67.0 \pm 10.0$ \\
\hline Gender(Male/Female) & $59 \%(13 / 9)$ \\
\hline History of hemo-dialysis(momths) & $59.5 \pm 31.6$ \\
\hline \multicolumn{2}{|l|}{ Etiology of end-stage renal disease } \\
\hline Diabetes Mellitus & $10(45 \%)$ \\
\hline Glomerulonephritis & $7(32 \%)$ \\
\hline Renal Sclerosis & $4(18 \%)$ \\
\hline Polycystic Kidney & $1(5 \%)$ \\
\hline \multicolumn{2}{|c|}{ ECG Findngs } \\
\hline LVH & $7(32 \%)$ \\
\hline CRBBB & $2(22 \%)$ \\
\hline WNL & $13(59 \%)$ \\
\hline \multicolumn{2}{|l|}{ Echocardiogram Findings } \\
\hline IVS & $13.5 \pm 1.3 \mathrm{~mm}$ \\
\hline PW & $12.8 \pm 1.3 \mathrm{~mm}$ \\
\hline EF & $68.8 \pm 6.2 \%$ \\
\hline \multicolumn{2}{|c|}{ ABI Findings } \\
\hline Abnormal $(\mathrm{ABI}<0.9)$ & $4(18 \%)$ \\
\hline Normal & $19(86.4 \%)$ \\
\hline \multicolumn{2}{|c|}{ Antihyperensive Drugs(number of patients) } \\
\hline 6 drugs & $3(14 \%)$ \\
\hline 5 drugs & $5(23 \%)$ \\
\hline 4 drugs & $9(41 \%)$ \\
\hline 3 drugs & $5(23 \%)$ \\
\hline 2 drugs & $1(5 \%)$ \\
\hline Mean dose of olmesaltan & $30.7 \pm 5.4 \mathrm{mg}$ \\
\hline $\begin{array}{l}\text { Calcium channel blolers(number of } \\
\text { patients) }\end{array}$ & $20(91 \%)$ \\
\hline Beta blokers & $17(77 \%)$ \\
\hline Alpha blokers & $13(59 \%)$ \\
\hline Methyldopa & $8(36 \%)$ \\
\hline Clonidine & $4(18 \%)$ \\
\hline Others & $6(27 \%)$ \\
\hline
\end{tabular}

Table 1: ECG: electrocardiogram; $A B I$ : ankle-brachial index; $L V H$ : left ventricula hypertrophy; CRBBB: complete right bundle branch block; WNL: within normal limits; IVS: thickness of the intraventricular wall; PW: thickness of the posterior wall; EF: ejection fraction. 


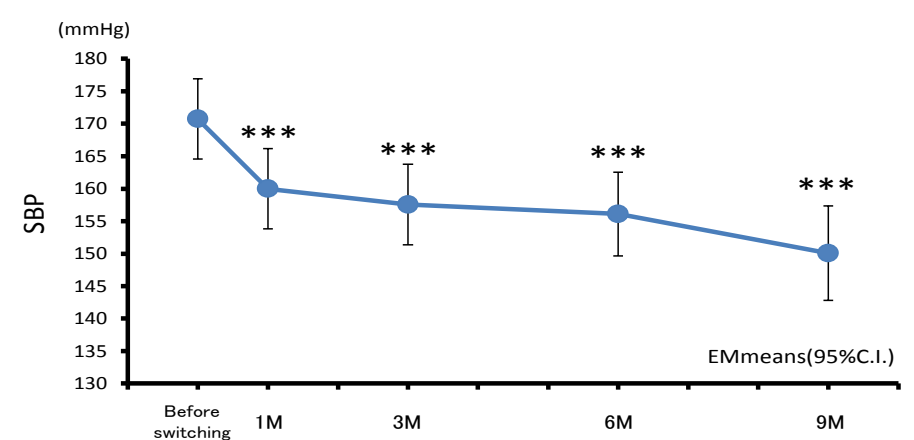

Mixed model pairwise comparisons test with Bonferroni correction

vs Before switching ${ }^{* * *} P<0.001$

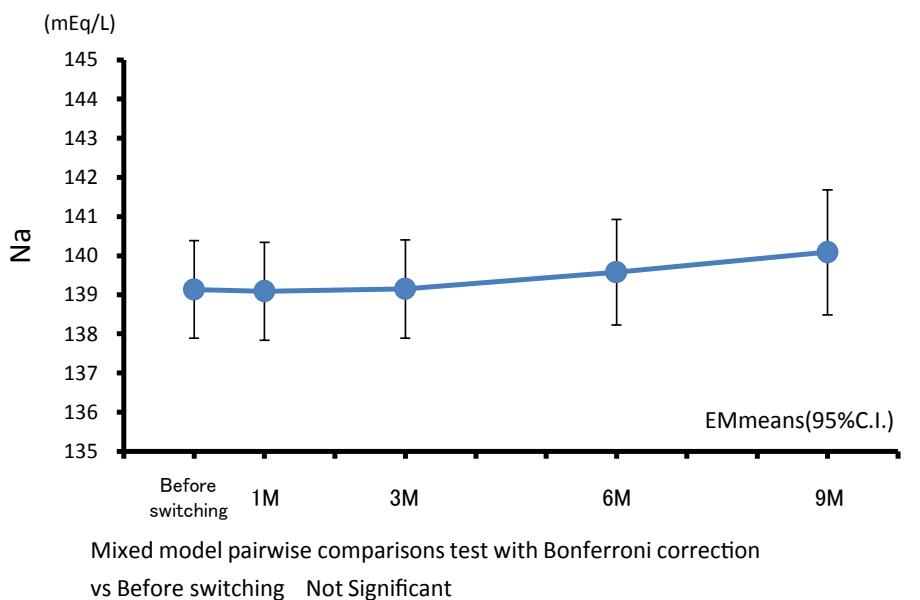

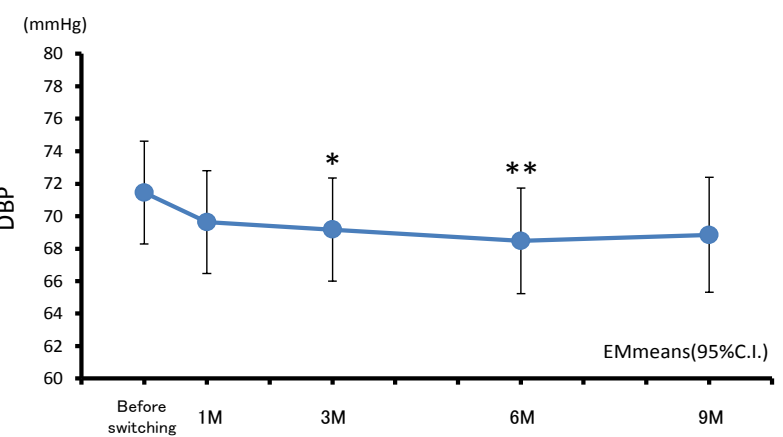

Mixed model pairwise comparisons test with Bonferroni correction vs Before switching ${ }^{*} P<0.05,{ }^{* *} P<0.01$

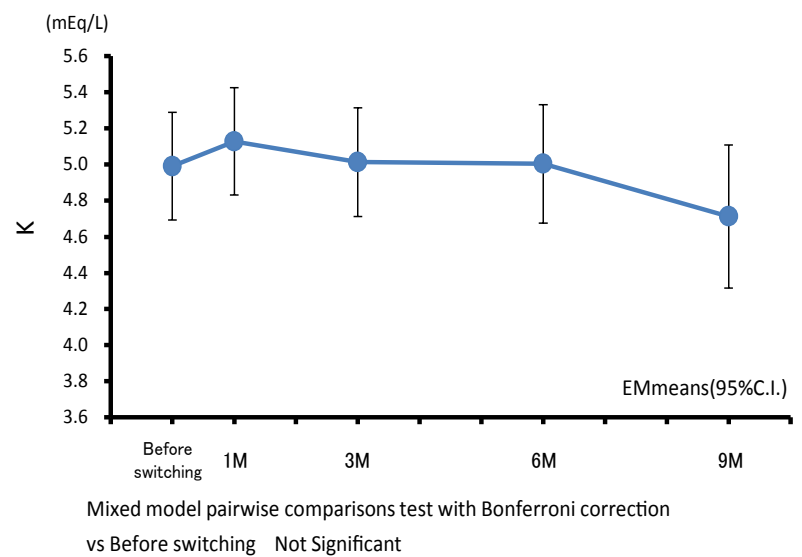

Figure 1: SBP: Systolic blood pressure; DBP: Diastolic blood pressure; Na: Serum-sodium; K: Serum-potassium.

hypertension [7,8]. Yang reported that ARBs reduce left ventricular hypertrophy in hemodialysis patients [28]. Takahashi reported that candesartan significantly reduced cardiovascular events in hemodialysis patients [29]. Suzuki reported that the use of ARBs may be effective in reducing non-fatal cardiovascular events in hemodialysis patients [30]. Tai reported a meta-analysis that showed that ARBs are associated with a greater reduction in left ventricular hypertrophy in hemodialysis patients [31]. However, Iseki reported that treatment with olmesartan did not significantly reduce the risks of major cardiovascular events or death among hypertension patients on chronic hemodialysis [32]. On the other hand, the combination of angiotensin receptor blockers and angiotensin converting enzyme inhibitors did not show additional benefits for left ventricular hypertrophy and the prognosis of hemodialysis patients [33]. Thus, intensive further research should not only address appropriate medications, but also the optimal BP in hemodialysis patients.

Azilsartan is a new ARB, and ARBs may reduce cardiac mortality rates in hemodialysis patients $[13,14,34]$. In an in vitro study, azilsartan was shown to have higher affinity for and slower dissociation from AT 1 receptors than other ARBs, including olmesartan, telmisartan, valsartan, and irbesartan $[13,14]$. It has been reported that once-daily administration of azilsartan produced a more potent 24 -h sustained antihypertensive effect than candesartan in Japanese patients with grade I-II essential hypertension, and it had an equivalent level of safety in a randomized, double-blind, comparative study [15]. It has also been reported that azilsartan provides greater BP reduction than candesartan over the entire 24-h monitoring period, as well as during the specific daytime, night-time, and early morning periods, by analysis of ambulatory blood pressure monitoring records [34]. Rothwell reported that increased residual variability in systolic BP in patients with treated hypertension is associated with a high risk of vascular events [35]. Nocturnal BP variation is important for preventing cardiovascular events, because non-dipping patterns are associated with sympathetic nervous activity. It has also been reported that in the non-dipping group, a greater reduction from baseline in nighttime than daytime BP was produced by treatment with azilsartan.

Switching from olmesartan to azilsartan significantly decreased home-measured blood pressure in hemodialysis patients with left ventricular hypertrophy in the previous study. Switching did not alter serum potassium levels. Lin also reported that renin angiotensin blockade is not associated with hyperkalemia in chronic hemodialysis patients [36]. Azilsartan seemed to be useful for controlling the BP of hemodialysis patients in whom calcium channel blockers are contraindicated because of their strong effects. Thus, the switch to azilsartan might improve the prognosis of hemodialysis patients. We suggest that the strong antihypertensive effect of azilsartan originates from a combination of its primary ARB class-effect and stronger suppression of the sympathetic nervous system.

There are some limitations to the present study. This was a retrospective study, ambulatory blood pressures were not measured, the number of patients was small. All patients dis not use the same type of machine in measurement of BP, and the long-term outcomes of patients were not analyzed. 
Citation: Sarikaya M, Bora F, Inci A, Sari F, Gul S, et al (2015) Comparison of Intraperitoneal Amino Acid and Oral Amino Acid Supplements in Peritoneal Dialysis Patients. J Nephrol Ther 5: 193. doi:10.4172/2161-0959.1000193

\section{Conclusion}

In conclusion, switching from olmesartan to azilsartan significantly and safely decreased home-measured blood pressure in hemodialysis patients.

\section{Conflicts of Interest}

The authors have no conflicts of interest to declare in relation to this article.

\section{Acknowledgements}

The authors would like to thank all patients, physicians, and medical staff who supported this study.

\section{References}

1. Tomita J, Kimura G, Inoue T, Inenaga T, Sanai T, et al. (1995) Role of systolic $\mathrm{BP}$ in determining prognosis of hemodialyzed patients. Am J Kidney Dis 25: 405-412.

2. Mittal SK, Kowalski E, Trenkle J, McDonough B, Halinski D, et al. (1999) Prevalence of hypertension in a hemodialysis population. Clin Nephrol 51: $77-82$.

3. Grekas D, Bamichas G, Bacharaki D, Goutzaridis N, Kasimatis E, et al. (2000) A Hypertension in chronic hemodialysis patients: current view on pathophysiology and treatment. Clin Nephrol 53: 164-168.

4. Rocco MV, Yan G, Heyka RJ, Benz R, Cheung AK, (2001) HEMO Study Group. Risk factors for hypertension in chronic hemodialysis patients: Baseline data from the HEMO study. Am J Nephrol 21: 280-288.

5. Agarwal R, Nissenson AR, Batlle D, Coyne DW, Trout JR, et al. (2003) Prevalence, treatment, and control of hypertension in chronic hemodialysis patients in the United States. Am J Med 115: 291-297.

6. Heerspink HJ, Ninomiya T, Zoungas S, de Zeeuw D, Grobbee DE, et al. (2009) Effect of lowering blood pressure on cardiovascular events and mortality in patients on dialysis:a systematic review and meta-analysis of randomised controlled trials. Lancet 373: 1009-1015

7. Agarwal R, Sinha AD (2009) Cardiovascular protection with antihypertensive drugs in dialysis patients: systematic review and meta-analysis. Hypertension 53: $860-866$

8. Rahman M, Griffin V, Kumar A, Manzoor F, Wright JT Jr, et al. (2002) A comparison of standardized versus "usual" blood pressure measurements in hemodialysis patients. Am J Kidney Dis. 39: 1226-1230

9. Ogura M, YamadaY, Terawaki H, Hamaguchi A, Kimura Y, et al. (2012) Home systolic blood pressure on the morning of dialysis days has prognostic impact for hypertensive hemodialysis patients. Clin Exp Nephrol 16: 427-432.

10. Agarwal R (2010) Managing hypertension using home blood pressure monitoring among haemodialysis patients--a call to action. Nephrol Dial Transplant 25: 1766-70.

11. Agarwal R (2005) Hypertension and survival in chronic hemodialysis patientspast lessons and future opportunities. Kidney Int 67: 1-13.

12. Agarwal R, Andersen MJ, Bishu K, Saha C (2006) Home blood pressure monitoring improves the diagnosis of hypertension in hemodialysis patients. Kidney Int 69: 900-906.

13. Zaiken K, Cheng JW (2011) Azilsartan medoxomil: a new Angiotensin receptor blocker. Clin Ther 33: 1577-1589.

14. Kajiya T, Christopher HO, Wang J, Vilardi R, Kurtz TW (2011) Molecular and cellular effects of azilsartan: a new generation angiotensin II receptor blocker. J Hypertens 29: 2476-2483.

15. Rakugi H, Enya K, Sugiura K, Ikeda $Y$ (2012) Comparison of the efficacy and safety of azilsartan with that of candesartan cilexetil in Japanese patients with grade I-II essential hypertension: a randomized, double-blind clinical study. Hypertens Res 35: 552-558.

16. White WB, Weber MA, Sica D, Bakris GL, Perez A, et al. (2011) Effects of the angiotensin receptor blocker azilsartan medoxomil versus olmesartan and valsartan on ambulatory and clinic blood pressure in patients with stages 1 and 2 hypertension. Hypertension 57: 413-420.
17. Ciccone MM, E Bilianou, Balbarni A, Gesuaaldo M, Ghiadoni L, et al.(2013) The controversial relationship between exercise and atrial fibrillation : clinical studies and pathological mechanisms. J Cardiovasc Med 14: 757-766.

18. D'Ascenzi F, Cameli M, Ciccone M, Maiello M, Modesti PA, et al. (2014) Task force on: 'Early markers of atherosclerosis : influence of age and sex. $J$ Cardiovasc Med. 2014

19. Agarwal R, Sinha AD, Pappas MK, Abraham TN, Tegegne GG (2014) Hypertension in hemodialysis patients treated with atenolol or lisinopril: a randomized controlled trial. Nephrol Dial Transplant 29: 672-681.

20. Shoji T, Tsubakihara Y, Fujii M, Imai E (2004) Hemodialysis-hypotension as an independent risk factor for two-year mortality in hemodialysis patients. Kidney Int 66: 1212-1220

21. Pun PH, Lehrich RW, Smith SR, Middleton JP (2007) Predictors of survival after cardiac arrest in outpatients hemodialysis clinics. Clin J Am Soc Nephro 2: 491-500.

22. Charra B, Bergstrom J, Scribner BH. (1998) Blood pressure control in dialysis patients: importance of the lag phenomenon. Am J Kidney Dis 32: 720-724.

23. Ishikawa J, Shimizu M, Sugiyama Edison E, Yano Y, Hoshide S, et al. (2014) Assessment of the reductions in night-time blood pressure and dipping induced by antihypertensive medication using a home blood pressure monitor. J Hypertens 32: 82-89.

24. Moriya H, Oka M, Maesato K et al. (2008) Weekly averaged blood pressure is more important than a single-point blood pressure measurement in the risk stratification of dialysis patients. Clin J Am Soc Nephrol 3: 416-422.

25. Moriya H, Ohtake T, Kobayashi S (2007) Aortic stiffness, left ventricular hypertrophy and weekly averaged blood pressure (WAB) in patients on haemodialysis. Nephrol Dial Transplant 22: 1198-1204.

26. Hoshide S, Kario K, Yano Y, Haimoto H, Yamagiwa K, et al. (2014) Association of morning and evening blood pressure at home with asymptomatic organ damage in the J-HOP Study. Am J Hypertens 27: 939-947.

27. Silva GVD, de Barros SD, Abensur H, Ortega K, Mion D Jr. (2009) Home blood pressure monitoring in blood pressure control among haemodialysis patients: an open randomized clinical trial. Nephrol Dial Transplant 24: 3805-3811.

28. Yang LY, Ge X, Wang YL, Ma KL, Liu H, et al. (2013) Angiotensin recepto blockers reduce left ventricular hypertrophy in dialysis patients: a metaanalysis. Am J Med Sci 345: 1-9.

29. Takahashi A, Takase H, Toriyama T, Sugiura T, Kurita $Y$ et al. (2006) Candesartan, an angiotensin II type-1 receptor blocker, reduces cardiovascula events in patients on chronic haemodialysis-a randomized study. Nephrol Dial Transplant 21: 2507-2512.

30. Suzuki H, Kaneko Y, Sugahara S, Ikeda N, Shoda J, et al. (2008) Effects of angiotensin receptor blockers on cardiovascular events in patients undergoing hemodialysis: an open-label randomized controlled trial. Am J Kidney Dis 52 501-506.

31. Tai DJ, Lim TW, James MT, Manns BJ, Tonelli M, et al. (2010) Cardiovascular effects of angiotensin converting enzyme inhibition or angiotensin receptor blockade in hemodialysis: a meta-analysis. Clin J Am Soc Nephrol 5: 623-630.

32. Iseki K, Arima H, Kohagura K, Komiya I, Ueda S, et al. (2013) Olmesartan Clinical Trial in Okinawan Patients Under OKIDS (OCTOPUS) Group. Effects of angiotensin receptor blockade (ARB) on mortality and cardiovascular outcomes in patients with long-term haemodialysis: a randomized controlled trial. Nephrol Dial Transplant $28: 1579-1589$

33. Chan KE, Ikizler TA, Gamboa JL, Yu C, Hakim RM, et al. (2011) Combined angiotensin-converting enzyme inhibition and receptor blockade associate with increased risk of cardiovascular death in hemodialysis patients. Kidney Int 80 : 978-985.

34. Rakugi $\mathrm{H}$, Kario $\mathrm{K}$, Enya $\mathrm{K}$, Igeta $\mathrm{M}$, Ikeda $\mathrm{Y}$ (2013) Effect of azilsartan versus candesartan on nocturnal blood pressure variation in Japanese patients with essential hypertension. Blood Pressure 22: 22-28.

35. Rothwell PM, Howard SC, Dolan E, O'Brien E, Dobson JE, et al. (2010) Prognostic significance of visit-to-visit variability, maximum systolic blood pressure, and episodic hypertension. Lancet 375: 895-905.

36. Lin HH, Yang YF, Chang JK, Ting IW, Kuo HL et al. (2009) Renin-angiotensin system blockade is not associated with hyperkalemia in chronic hemodialysis patients. Ren Fail 31: 942-945. 